\title{
Primary synovial sarcoma thyroid: an unusual presentation
}

\author{
Pallavi Srivastava $^{1}$, Nidhi Anand ${ }^{1}$, Nuzhat Husain ${ }^{1}$ \\ ${ }^{I}$ Department of Pathology, Dr Ram Manohar Lohia Institute of Medical Science, Uttar Pradesh, India
}

\section{Keywords:}

Epithelial membrane antigen;

Synovial sarcoma;

Thyroid;

Transducin-like enhancer

of split-1;

\begin{abstract}
Primary Synovial sarcoma of the thyroid gland is a rare sarcoma. We report a case of synovial sarcoma of the thyroid gland in a 2-yr-old boy presenting with a palpable progressively increasing neck mass, high resolution ultrasound revealed a heterogeneous lesion measuring $5 \times 4 \mathrm{~cm}$ identified in the right lobe compressing the left lobe. A total thyroidectomy was performed and grossly both the lobes were involved. Histologically, the tumor was a biphasic synovial sarcoma which was confirmed by immunohistochemical markers showing positive expression for vimentin, Epithelial membrane antigen \&Transducin-like enhancer of split-1. This is an unusual location for the occurrence of primary synovial sarcoma and aggressive nature the early diagnosis is difficult, and no definite treatment regimens are being defined due to the rarity of neoplasm.
\end{abstract}

\section{Correspondence:}

Dr. Nidhi Anand, $M D$

Department of Pathology,

Dr Ram Manohar Lohia Institute of Medical Sciences, Vibhuti Khand,

Gomti Nagar, Lucknow, Uttar Pradesh, India.-226010

ORCID ID: 0000-0003-1831-9063

Email :nidhi.anand42@gmail.com

Reveived : April $6^{\text {th }} 2020 ;$ Accepted : July $31^{\text {ts } 2020}$

Citation: Srivastava P, Anand N, Husain N. Primary synovial sarcoma thyroid: an unusual presentation. J Pathol Nep 2020;10:1776-8. DOI: 10.3126/jpn.v10i2.28358

Copyright: This is an open-access article distributed under the terms of the Creative Commons Attribution 4.0 International License, which permits unrestricted use, distribution, and reproduction in any medium, provided the original author and source are credited.

\section{INTRODUCTION}

Synovial sarcoma is a mesenchymal neoplasm that accounts for $10-20 \%$ of the soft tissue of the extremities with an onset in the adolescent and young adult. ${ }^{1,2}$ The head and neck region is the second most frequent site, representing $\sim 5 \%$ of the cases, ${ }^{3}$ primary thyroid synovial sarcoma occurrence is quite rare, such locations make the recognition and differential diagnosis more difficult and the surgical treatment more complex because of the proximity of noble anatomic structures. ${ }^{4}$ To the best of our knowledge, twelve cases have been reported to date. ${ }^{4-10}$ Here we report a case of a 2-year-old boy presenting with progressively increasing neck mass treated by total thyroidectomy followed by chemotherapy.

\section{CASE REPORT}

A 2-year-old boy presented with chief complaints of wheezing, hoarseness of voice, dysphagia, and neck swelling for 3 months which rapidly progressed to diffuse 


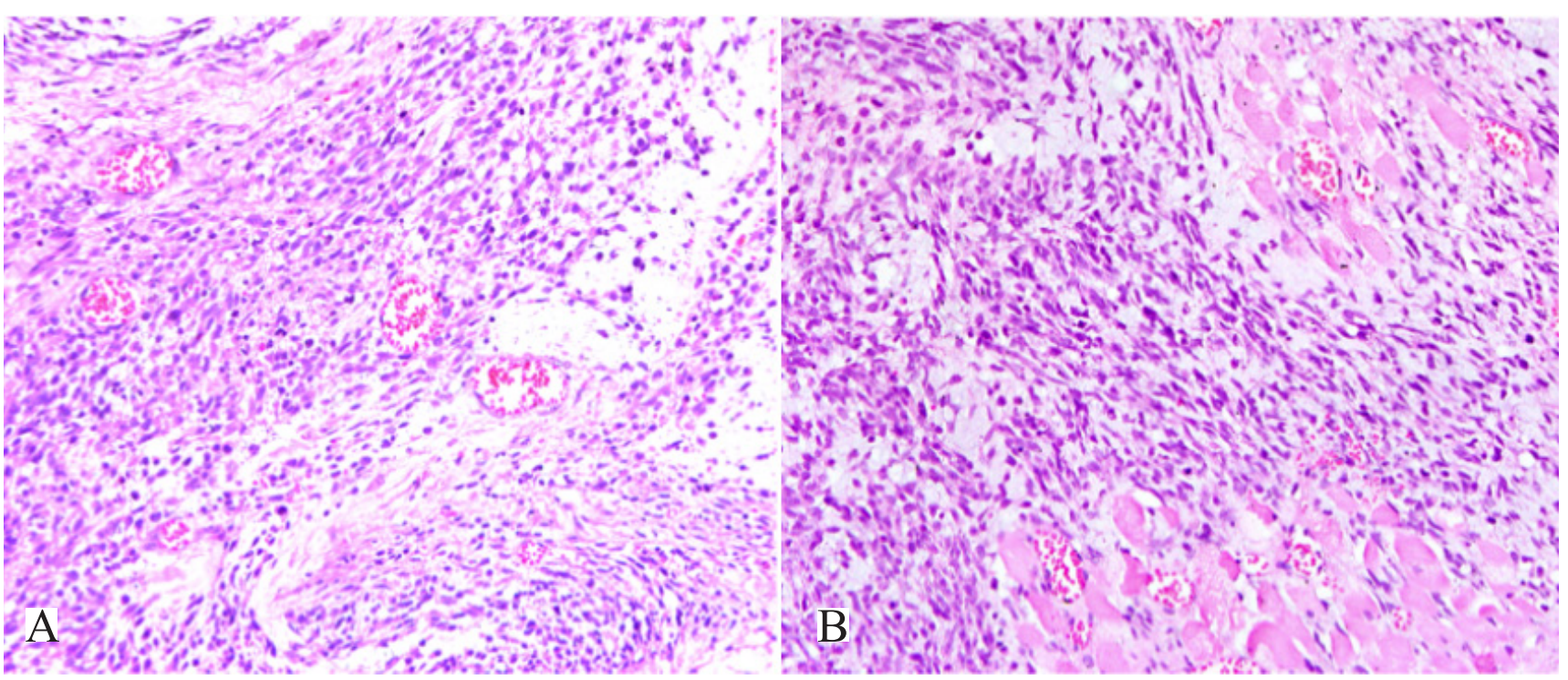

Figure 1: A) The tumor was composed of ovoid to spindle cells, moderately pleomorphic nuclei, clumped chromatin, conspicuous nucleoli, and moderate eosinophilic cytoplasm disposed of in myxoid stroma (HE stain; X200). B) The tumor was infiltrating the surrounding muscle (HE stain; X200).

neck swelling. On examination neck swelling measuring $6.0 \times 4.0 \mathrm{~cm}$ was identified which moved on deglutition. On palpation, the swelling was non-tender, firm to hard. All laboratory tests, including thyroid function tests, were unremarkable. High-resolution ultrasonography was performed which revealed a heterogenous lesion measuring $5 \times 4 \mathrm{~cm}$ involving the right lobe, compressing the left lobe. Because of the findings, a total thyroidectomy was performed. The resected mass measured $5.5 \times 4.5 \times 2.5$ $\mathrm{cm}$. Cut surface showed an ill-circumscribed solid white, heterogeneous mass with focal myxoid change. The tumor was disposed of in lobules comprising of hypocellular and hypercellular areas with focal hemangiopericytoma pattern. The lobule was predominantly comprised of ovoid to spindle cells, moderately pleomorphic nuclei, clumped chromatin, conspicuous nucleoli, and moderate eosinophilic cytoplasm disposed of in myxoid stroma (fig. 1A) Mitosis were evident (10-12/10HPF). Areas of necrosis were not seen. The tumor was seen infiltrating the surrounding adipose tissue and muscle (fig.1B).

Immunohistochemical staining for Vimentin, CD-99, Bcl-2, TLE-1was strongly positive (fig.2A-D) and showed focal positive for Pan CK and negative for desmin, S-100, CD 34 , and myogenin and was diagnosed as synovial sarcoma of the thyroid.

The patient underwent surgery, which was followed by 6 cycles of chemotherapy comprising doxorubicin and ifosfamide. The patient was on regular follow up and there were no signs of recurrence after 1 year of follow up.

\section{DISCUSSION}

Synovial sarcoma is a soft tissue neoplasm that accounts for $10 \%$ of all the soft tissue sarcoma while head and neck synovial sarcoma usually accounts for $10 \%$ of all the synovial sarcoma, the most common location is hypopharynx and retropharynx..$^{1-3}$ Primary synovial sarcoma of the thyroid are extremely rare, to the best of our knowledge only twelve cases are reported in past. The synovial sarcoma usually occurs in young adult and adolescents, however, none of the cases were reported in less than 5 years of age as in our case. The presenting symptoms are neck mass and hoarseness of voice, the diagnosis is usually delayed due to the unusual location of the tumor and it follows an aggressive course presenting with frequent relapses and distant metastasis. ${ }^{2,8}$ Ultrasonography is used as the first modality to diagnose the nodular lesion in the thyroid parenchyma followed by computed tomography (CT) and magnetic resonance imaging (MRI). We report a case of primary synovial sarcoma of the thyroid gland in a 2-year-old boy which is a rare presentation in this age group, treated by surgery and adjuvant chemotherapy with good response. In our case, an early diagnosis and appropriate treatment lead to a better prognosis despite the head and neck being a high-risk site for tumour progression, local relapses, and metastasis. Histopathology reveals a spindle cell neoplasm so a spindle cell variant of medullary carcinoma, anaplastic carcinoma, and spindle epithelial tumor with thymus-like differentiation (SETTLE) should be considered in the differential diagnosis and ruled out by proper IHC panel before diagnosing primary synovial sarcoma of the thyroid gland. SETTLE is a close differential of synovial sarcoma with similar clinical, histologic, and IHC features, however, SETTLE shows bland uniform spindle cells as compared to moderately pleomorphic, mitotically active tumor cells in synovial sarcoma which show $>80 \%$ positivity for TLE1 . The spindle cell variant of medullary carcinoma is also included in the differential, the following features may help in differentiating from synovial sarcoma including older age group, characteristic nuclear features favouring medullary 

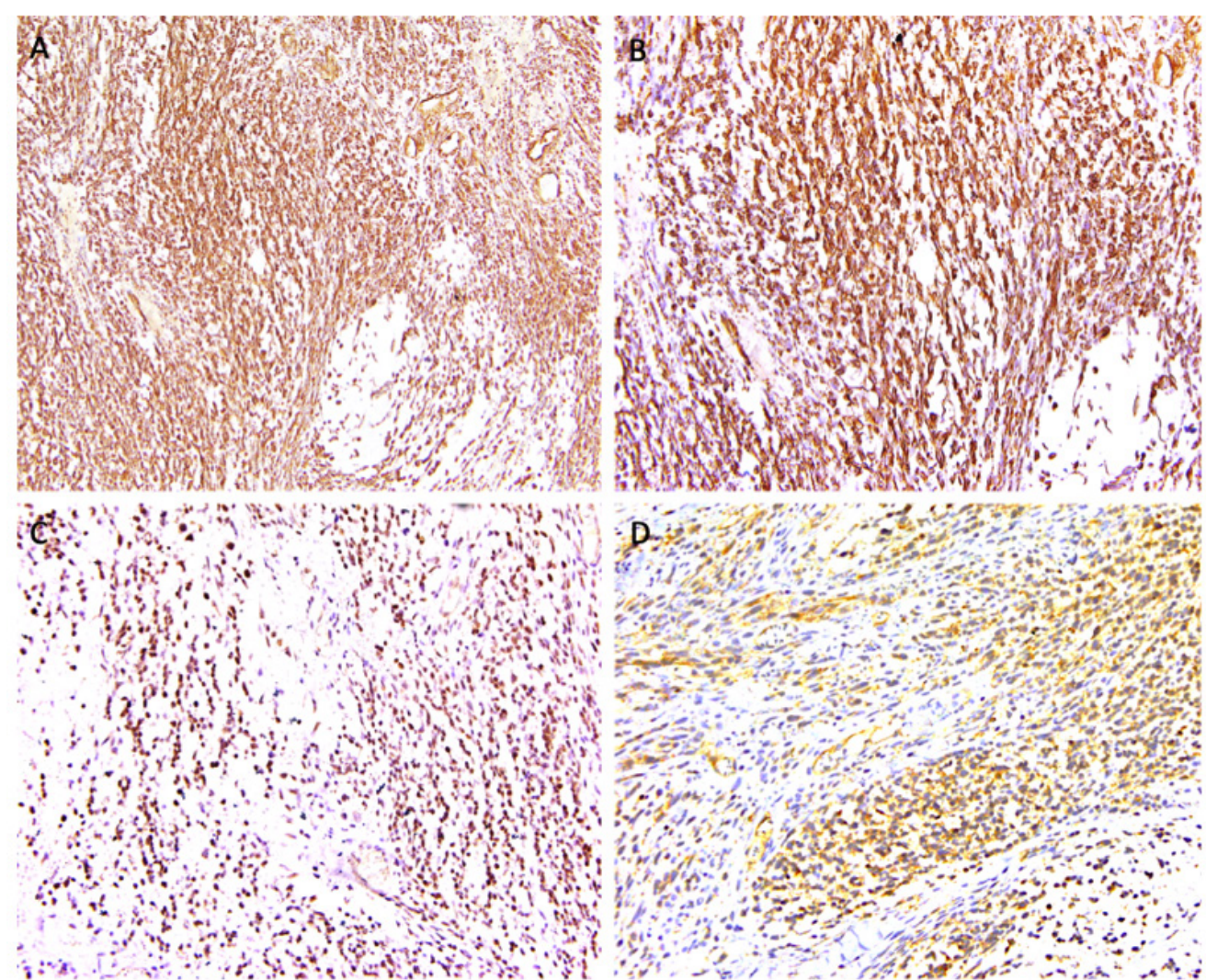

Figure 2: Immunohistochemistry findings: Tumor showing diffuse strong positive expression vimentin(A), CD99(B) \& TLE-1(C) with focal expression for Bcl-2 (D). [Original magnification x20 $(A-D)]$.

carcinoma and positive for synaptophysin, chromogranin, calcitonin, and presence of amyloid deposits. ${ }^{7}$ A cytogenetic study may provide conclusive evidence to confirm the diagnosis of synovial sarcoma by detecting the SYT-SSX fusion gene transcripts using the reverse transcriptasepolymerase chain reaction method. ${ }^{7}$

\section{REFERENCES}

1. Pappo AS, Fontanesi J, Luo X, et al. Synovial sarcoma in children and adolescents: The St Jude Children's Research Hospital experience. J Clin Oncol. 1994;12:2360-6. $\underline{\text { Crossref }}$

2. Ferrari A, De Salvo GL, Brennan B, et al. Synovial sarcoma in children and adolescents: the European Pediatric Soft Tissue Sarcoma Study Group prospective trial (EpSSG NRSTS 2005) Ann Oncol. 2015;26:567-72. $\underline{\text { Crossref }}$

3. Al-Daraji W, Lasota J, Foss R, Miettinen M. Synovial sarcoma involving the head: Analysis of 36 cases with predilection to the parotid and temporal regions. Am J Surg Pathol. 2009;33:1494-503. Crossref

4. Boudin L, Fakhry N, Chetaille B, et al. Primary Synovial Sarcoma of the Thyroid Gland: Case Report and Review of the Literature. Case Reports in Oncology. 2014;7:6-13. $\underline{\text { Crossref }}$
5. Ryu CH, Cho KJ, Choi SH. Synovial sarcoma of the thyroid gland. Clin Exp Otorhinolaryngol. 2011;4:204-6. Crossref

6. Kikuchi I, Anbo J, Nakamura S, et al. Synovial sarcoma of the thyroid. Report of a case with aspiration cytology findings and gene analysis. Acta Cytol. 2003;47:495-500. Crossref

7. Jang KS, Min KW, Jang SH, et al. Primary synovial sarcoma of the thyroid gland. J Korean Med Sci. 2007;22:154-8. $\underline{\text { Crossref }}$

8. Shi RL, Qu N, Gaol L, Luz W, Sung H, Jiq H. Primary synovial sarcoma of the thyroid with locally repeated relapses in short periods: A case report. Biomedical Reports. 2016;5(1):79-82. $\underline{\text { Crossref }}$

9. Ghafouri A, Anbara T, Mir A, Lashkari M, Nazari M. Thyroid synovial sarcoma: a case report. Acta Med Iran. 2013;51:69-72. $\underline{\text { Website }}$

10. Hassouna AH, Salama AI. Synovial Sarcoma of Thyroid Gland: Case Report and Review of Literature. Glob J Medical Clin Case Rep. 2017;4: 051-2. Website 